\title{
Sınıf Öğretmeni Adaylarının Afet Bilinci Algısı ve Deprem Bilgi Düzeylerinin İncelenmesi
}

\author{
Özgür TEKIN \\ Aile Sosyal Çalışma Bakanlığı Kırşehir Il Müdürlüğü \\ ozgurtekin40@hotmail.com \\ ORCID ID: 0000-0001-9404-4941 \\ Yurdal DİKMENLİ \\ Kırşehir Ahi Evran Üniversitesi Eğitim Fakültesi \\ dikmenliy@hotmail.com \\ ORCID ID: 0000-0003-3738-3095
}

\begin{tabular}{lrr} 
Araştırma Makalesi & DOI: $10.31592 /$ aeusbed.811043 \\
\hline Geliş Tarihi: 15.10 .2020 & Revize Tarihi: 03.12 .2020 & Kabul Tarihi: 16.12 .2020
\end{tabular}

\section{Atıf Bilgisi}

Tekin, Ö. ve Dikmenli, Y. (2021). Sınıf öğretmeni adaylarının afet bilinci algısı ve deprem bilgi düzeylerinin incelenmesi. Ahi Evran Üniversitesi Sosyal Bilimler Enstitüsü Dergisi, 7(1), 258-271.

\section{ÖZ}

Bu araştırmanın amacı, sınıf öğretmeni adaylarının afet bilinci algı düzeyleri, deprem bilgi düzeyleri ve afet bilinci algı düzeyi ile deprem bilgisi arasındaki ilișkileri incelemektir. Araştırma nicel araştırma yaklaşımlarından ilişkisel tarama modeline göre yapılmıştır. Araştırmanın örneklem grubunu 2018-2019 eğitim-öğretim yılında Ahi Evran Üniversitesi ve Amasya Üniversitesi Eğitim Fakültesi, Temel Eğitim Anabilim Dalı, Sınıf Eğitimi Bilim Dalında öğrenim görmekte olan 552 öğretmen adayı oluşturmaktadır. Çalışmada kolay ulaşılabilir örnekleme yöntemi kullanılmıştır. Araştırmanın veri toplama aracı olarak; Afet Bilinci Algı Ölçeği ve Deprem Bilgisi Başarı Testi kullanılmıştır. Elde edilen verilerin analizinde paket veri analiz programı kullanılmıştır. Verilerin analizi sonucunda; sınıf öğretmeni adaylarının yüksek düzey afet eğitimi, afet öncesi, yanlış afet ve afet bilinci algısına, orta düzey afet sonrası bilinç algısına sahip oldukları tespit edilmiștir. Yine sınıf öğretmeni adaylarının orta düzey deprem öncesi, deprem anı ve genel deprem bilgi düzeyine, düşük düzey deprem sonrası bilgi düzeyine sahip oldukları tespit edilmiştir. Ayrıca sınıf öğretmeni adaylarının afet bilinci ile deprem bilgisi arasında pozitif yönde ve istatistiksel açıdan anlamlı bir ilişki olduğu belirlenmiştir.

Anahtar Kelimeler: Sınıf Öğretmeni Adayları, Afet Bilinci Algısı, Deprem Bilgisi,

\section{Analysis of Pre-Service Classroom Teachers' Disaster Awareness Perception and Earthquake Knowledge Level}

\section{ABSTRACT}

The purpose of this study is to analyse the pre-service classroom teachers' disaster awareness perception, earthquake knowledge level and the relationship between disaster awareness level and earthquake knowledge. This study uses relational survey model among quantitative research methods. The sample of this study consists of 552 pre-service classroom teachers studying in Ahi Evran University and Amasya University Education Faculty, Primary Education Department, Class Education Branch in the 2018-2019 academic year. This study uses a convenience sampling method. As data collection tools, Disaster Awareness Perception Scale and Earthquake Knowledge Success Test are used. The obtained data are analysed with a package data analysis program. The obtained data are investigated with quantitative analysis methods. For the descriptive presentation of the obtained data, frequency, percentage, average and standard deviation are used. At the end of the data analysis, it is determined that pre-service primary school teachers have high-level disaster education, pre-disaster, incorrect disaster and disaster awareness perception and medium-level post-disaster awareness perception. Again, it is determined that pre-service primary school teachers have medium-level pre-earthquake, earthquake and general earthquake knowledge level and low-level post-earthquake knowledge. Additionally, it is determined that pre-service classroom teachers' disaster awareness and earthquake knowledge had a positive and statistically significant relationship. Keywords: Classroom Teacher Candidates, Disaster Awareness Perception, Earthquake Knowledge. 


\section{Giriş}

Doğada her gün kısa veya uzun süren doğal olaylar meydana gelmektedir. Bu olayların hepsi insanlara zarar veren özelliklere sahip değildir. Doğal olaylar insan ve çevresine zarar verdiğinde afet özelliği kazanarak, insanların faaliyetleri sonucunda afet haline dönüşmektedir.

İnsanlar için fiziksel, sosyal ve ekonomik kayıplar doğuran, insan faaliyetlerini ve normal yaşamı kesintiye uğratarak toplulukları olumsuz yönde etkileyen; doğal, teknolojik ve insan kaynaklı faktörlerin oluşturduğu olaylar afet olarak tanımlanmaktadır (Ergünay, 2008). Afetlerden korunmak ya da onlardan gelebilecek zararı azaltmak için etkili bir afet bilincine sahip olunmalıdır. Bu nedenle okullarda doğru, kalıcı ve katılımcı bir afet eğitimi verilerek afetin zararları en aza indirilebilir (Aydın, 2010). Bu bilgilendirme ve bilinçlendirme işini okullarda ilk olarak yapacak olanların öğretmenler olduğu düşünülürse, öncelikle öğretmen adaylarının afet eğitimi ve bilinci konusunda yeterli bilgi, bilinç ve tecrübeye sahip olması gerekmektedir.

Türkiye'de meydana gelen ve önemli ölçüde yıkımlara neden olan doğal afetlerden birisi de depremlerdir (Şahin, 1991). Kaynağını yerin içinden alan ve yeryüzünde titreşimlere neden olan, kısa süreli doğal olaylar deprem olarak tanımlanmaktadır (İzbırak, 1992; Sür, 1993). Depremin nerelerde meydana gelebileceği tahmin edilebilirken, ne zaman olacağını tahmin etmek mümkün değildir. Ancak insanlar depreme karşı çeşitli önlemler alarak hasarı en aza indirme kabiliyetine sahiptir. Bu önlemlerin başında etkili ve sürekli deprem eğitimi gelmektedir (Karakuş, 2013). Öcal'a (2005) göre deprem eğitiminin içinde depremi oluşturan yerin yapısal özellikleri, depremle ilgili temel bilgiler, deprem esnası ve sonrasında oluşabilecek zararlar ve bu zararlarından korunma yollarının öğretim süreci yer almaktadır.

Deprem eğitimi, okulöncesi eğitiminden başlayıp yaşam boyu devam etmesi gereken bir eğitim şeklidir (Karakuş, 2013). Depremler, bugünün teknolojisi ile önceden tahmini mümkün olmayan bir doğal afet olduğu için meydana geldikleri yerlerde farklı boyut ve büyüklükte zararlara neden olmaktadirlar. Okullar topluma kitlesel olarak deprem eğitimin en iyi verilebileceği mekanlardır. Etkili bir afet ve deprem eğitimi ile depremlerin zararlarından korunmak ya da gelebilecek zararlar azaltılabilmektedir (Aydın, 2010). Deprem konusunda eğitimli bireyler depremden daha az zarar görürken, eğitimsiz bireylerin depremden daha fazla etkileneceği de bir gerçektir (Demirkaya, 2007). Çünkü Hurnen ve McClure (1997)'a göre, deprem bilgi düzeyi yüksek adayların deprem zararlarını azaltma çalışmalarına daha fazla katıldıkları görülmüştür. Buna göre, bireylerin deprem bilgi düzeyleri arttıkça depremlerden etkilenme düzeyleri ile doğanın ölümcül ve yıkıcı etkileri azalmaktadır (Öcal, 2007a).

Alan yazın incelendiğinde afet bilinci ile ilgili (Coveleski, 2014; Özgen, Ünald1 ve Bindak, 2011; Özkazanç ve Yüksel, 2015; Yazıcı ve Ulu Kalın, 2018; Dikmenli ve Yakar, 2019), deprem eğitimi ve bilinci ile ilgili (Öcal, 2005; Tanaka, 2005; Öcal, 2007b; Gülay, 2010; Öztürk, 2013; Değirmençay ve Cin, 2016; Çoban, 2017; Kıvrak, 2019; Çakar, 2008; Fetihi ve Gülay, 2011; Karakuş, 2013; Demirci ve Yıldırım, 2015; Taş, 2003; Başıüyük, 2004; Shaw, Kobayashi, ve Kobayashi, 2004; Panić vd., 2013) çok sayıda çalışma olduğu görülmektedir. Ancak afet bilinci algısı ile deprem bilgi düzeyi arasında ilişki olup olmadığını belirlemeye yönelik araştırmaya rastlanmamıştır. $\mathrm{Bu}$ nedenle ögretmen adaylarının afet bilincine ve deprem bilgisine sahip olmalarının ileride yetiştirecekleri öğrencilere bu bilinci ve bilgiyi aktarmaları konusunda önemli olduğu düşünülerek araştırmada ortaya çıkacak olan sonuçların ise bundan sonra yapılacak olan araştırmalara 1şık tutacağı düşünülmektedir. Bu çalışmanın amacı sınıf öğretmen adaylarının afet bilinci algı düzeyini, deprem bilgi düzeyini belirlemek ve afet bilinci ile deprem bilgisi arasında ilişki olup olmadığını tespit etmektir. 


\section{Yöntem}

\section{Araştırma Modeli/Deseni}

$\mathrm{Bu}$ araştırma, sınıf öğretmen adaylarının afet bilinci algısı ve deprem bilgi düzeylerini incelemek ve aralarındaki ilişkiyi belirlemek amacıyla yapılan tarama modellerinden ilişkisel tarama modelinde yapılan nicel bir araştırmadır. İlişkisel tarama modeli iki ya da daha fazla değişken arasında ilişki olup olmadığı ve ilişkinin varlığı durumunda bunun yönü ortaya koyulmaya çalışılmıştır. Bu modelle, değişkenler arasındaki ilişki ya da ilişsisizlik belirlenmiştir (Gay ve Diehl, 1992; Karasar, 1999; Sönmez ve Alacapınar, 2011).

\section{Evren ve Örneklem}

Araştırmanın çalışma evreni, Ahi Evran Üniversitesi ve Amasya Üniversitesi Eğitim Fakültesi sınıf eğitimi anabilim dallarında öğrenime devam eden öğretmen adaylarından oluşmaktadır. Araştırmanın örneklemini, 2018 - 2019 eğitim-öğretim yılında Ahi Evran Üniversitesi ve Amasya Üniversitesi'nde öğrenim gören sınıf öğretmeni adayları oluşturmaktadır. Araştırmaya gönüllük esasına göre araştırmacıların kolay ulaşabilmesinden dolayı uygun durum örnekleme tekniği kullanılmıştır. Örneklemi Ahi Evran Üniversitesi'nden 312, Amasya Üniversitesi'nden ise 240 sınıf öğretmeni adayı olmak üzere 552 sınıf öğretmeni adayı oluşturmuştur.

\section{Veri Toplama Araçları}

Araştırmada, sınıf öğretmeni adaylarının afet bilinci algı düzeylerini belirlemek için "Afet Bilinci Algı Ölçeği”, sınıf öğretmeni adaylarının deprem bilgi düzeyini belirlemek için ise "Deprem Bilgisi Başarı Testi” kullanılmıştır.

\section{Afet Bilinci Algı Ölçeği}

Afet bilinci algısı verilerinin toplanmasında Dikmenli, Yakar ve Konca (2018) tarafindan geliştirilen 5'li likert tipinde "Afet Bilinci Alg1 Ölçeği” kullanılmıştır. Ölçekteki maddeler; (1) "kesinlikle katılmıyorum", (2) "katılmıyorum", (3) "kararsızım", (4) "katıllyorum" ve (5) "kesinlikle katıliyorum" şeklinde düzenlenerek puanlanmıştır. Ölçek toplamda 36 maddeden oluşmakta ve 27 olumlu, 9 olumsuz madde bulunmaktadır. 12, 22, 23, 24, 25, 26, 27, 28 ve 29 numaralı maddeler negatif olarak belirlenmiş, veri analizleri yapılmadan önce bu maddeler ters kodlanmıştır. Afet bilinci algı ölçeği 4 faktörden oluşmaktadır. Bunlar 13 maddeden oluşan afet eğitimi bilinci, 8 maddeden oluşan afet öncesi bilinç, 8 maddeden oluşan yanlış afet bilinci ve 7 maddeden oluşan afet sonrası bilinç alt boyutlarıdır. Ölçeğin geçerliliği iki farklı yöntem, faktör analizi ve diskriminant analizi ile incelenmiştir. Madde-toplam korelasyonları, atfedilen faktör tarafından ölçülebilen maddelerin her birinin kapsamını belirlemek için hesaplanmıştır. Ölçeğin geçerliliğini tespit etmek için faktör analizi yapılmış, madde faktörü toplam korelasyonları ve madde ayırt etme değerleri hesaplanmıştır. Ölçeğin güvenilirliğini belirlemek için iç tutarlılık düzeyi ve kararlılık düzeyleri hesaplanmıştır. Cronbach alpha güvenirlik katsayısının 0.722 olduğu belirlenmiştir. Ölçekten yüksek puanlar almak öğretmen adaylarının afet farkındalığının yüksek olduğu anlamına gelmektedir. Yapılan araştırmada ise ölçeğin cronbach alpha güvenirlik katsayısı 0.911 olarak belirlenmiştir.

\section{Deprem Bilgisi Başarı Testi}

Verilerin toplanmasında; araştırmacılar tarafından oluşturulan Deprem Bilgisi Başarı Testi uygulanmıştır. Literatür taranarak 50 maddelik bir soru havuzu oluşturulmuştur. Bu sorular iki alan uzmanı, bir ölçme değerlendirme uzmanı ve bir dil uzmanı tarafından incelenerek soru sayısı 32'ye düşürülmüştür. Başarı testi ön uygulaması aynı üniversitelerdeki 130 sınıf öğretmeni adayına bu 32 soru üzerinden yapılmıştır. Testin uygulanmasından sonra test maddelerin güçlüğü ve ayırt ediciliği incelenmiştir. Madde güçlüğü 0.30 'un altında olan 1 madde ile madde ayırt ediciliği 0.20 'nin altında olan 7 madde test kapsamından çıkartılarak 24 maddelik testin nihai hali oluşturulmuştur. Bu hali ile asıl uygulama gerçekleştirilmiştir. Test sonucunda elde edilen değerlerin güvenirliği için iç tutarlık katsayısı hesaplanarak cronbach alpha değeri 0,78 olarak belirlenmiştir. 


\section{Verilerin Toplanması ve Analizi}

Araştırmadan elde edilen veriler nicel analiz yöntemleri kullanılarak incelenmiştir. Elde edilen verilerin betimsel olarak sunulması amaciyla frekans, yüzde, ortalama ve standart sapma kullanılmıştır. $\mathrm{Bu}$ araştırma sürecinde verilerin normal dağılıp dağılmaması ve grupların varyanslarının eşit olup olmaması öncelikle incelenmiştir. Normal dağılım gösteren grupların karşılaştırılmasında iki alt değişkenli olan bağımsız örneklemler için t testi ve ikiden fazla alt değişkenli olan bağımsız örneklemler için ise tek yönlü varyans analizi (ANOVA) testleri yapılmıştır. Bunun yanı sıra, normal dağılım göstermeyen grupların karşılaştırılmasında Mann Whitney U testi ve Kruskal Wallis H testleri kullanılmıştır. Ayrıca değişkenler arasında ilişki olup olmadığını belirlemek için Pearson Korelasyon Analizi yapılarak ilişkinin yönü ve şiddeti belirlenmiştir. Analizlerde anlamlılık düzeyi 0,05 olarak kabul edilmiştir.

Afet Bilinci Alg1 Ölçeğinin puanlamasında, "Kesinlikle katılmıyorum" 1 puan, "Katılmıyorum" 2 puan, "Kararsızım" 3 puan, "Katıllyorum" 4 puan, "Kesinlikle katıllyorum" 5 puan olarak değerlendirilmiştir. Ölçekte negatif olarak belirlenmiş olan maddeler veri analizinde ters puanlanmıştır. Ölçeğin faktörlere yönelik cronbach alpha değerlerinin sırasıyla; 0.750, 0.769, 0.696 ve 0.672 olduğu belirlenmiştir. Bu sonuçlara baktı̆̆ımızda ölçeğin genelinin ve her bir faktörün tutarlı ölçümler yaptığı söylenebilir. Ölçeğin mümkün olan en düşük puanı 36, en yüksek puanı ise 180'dir. Tablo 1' de ölçeğin alt boyutları ile ilgili bilgiler sunulmuştur.

Tablo 1

Sinıf Öğretmeni Adaylarının Afet Bilinci Algı Düzeylerinin Alt Boyutlarının Belirlenmesinde Kullanilan Minimum ve Maksimum Puanlar

\begin{tabular}{lccc}
\hline $\begin{array}{l}\text { Afet Bilinci Alt } \\
\text { Boyutları }\end{array}$ & Madde Sayısı & Minimum Puan & Maksimum Puan \\
\hline Afet Eğitimi Bilinci & 13 & 13 & 65 \\
Afet Öncesi Bilinç & 8 & 8 & 40 \\
Yanlış Afet Bilinci & 8 & 8 & 40 \\
Afet Sonrası Bilinç & 7 & 7 & 35 \\
\hline Toplam & $\mathbf{3 6}$ & $\mathbf{3 6}$ & $\mathbf{1 8 0}$ \\
\hline
\end{tabular}

Afet Bilinci Algı Ölçeğinin tamamından alınabilecek puanlar 36 ile 180; afet eğitimi bilinci alt boyutu puanları 13 ile 65, afet öncesi bilinç alt boyutu puanları 8 ile 40, yanlış afet bilinci alt boyutu puanları 8 ile 40 ve afet sonrası bilinç alt boyutu puanları ise 7 ile 35 puan arasında değişmektedir.

Deprem Bilgisi Başarı Testi toplam 24 sorudan ve çoktan seçmeli (5 şıklı) sorulardan oluşmaktadır. Her sorunun doğru cevabı 1 puan yanlış cevabı 0 puan olduğu için bu testten alınabilecek en düşük puan 0 , en yüksek puan ise 24' tür. Tablo 3' te ölçeğin alt boyutları ile ilgili bilgiler sunulmuştur.

Tablo 2

Sinı Öğretmeni Adaylarının Deprem Bilgi Düzeylerinin Alt Boyutlarının Belirlenmesinde Kullanılan Minimum ve Maksimum Puanlar

\begin{tabular}{lccc}
\hline $\begin{array}{l}\text { Deprem Bilgisi } \\
\text { Alt Boyutları }\end{array}$ & Madde Sayısı & Min. Puan & Mak. Puan \\
\hline Deprem Bilgisi & 6 & 0 & 6 \\
Deprem Öncesi Bilgi & 6 & 0 & 6 \\
Deprem Anı Bilgisi & 6 & 0 & 6 \\
Deprem Sonrası Bilgi & 6 & 0 & 6 \\
\hline Toplam & $\mathbf{2 4}$ & $\mathbf{0}$ & $\mathbf{2 4}$ \\
\hline
\end{tabular}


Deprem Bilgisi Başarı Testinin tamamından alınabilecek puanlar 0 ile 24 puan arasındadır. Deprem bilgisi alt boyutu puanları 0 ile 6 , deprem öncesi bilgi alt boyutu puanlar1 0 ile 6 , deprem an bilgisi alt boyutu puanı 0 ile 6 ve deprem sonrası bilgi alt boyutu puanları ise 0 ile 6 puan arasinda değişmektedir.

\section{Araştırma Etiği}

Çalışmanın problemi belirlendikten sonra verilerin toplanması için ihtiyaç duyulan ölçeklerin belirlenmesine geçilmiştir. Literatür taranarak sınıf öğretmeni adaylarının afet bilinci algısını belirlemek için Dikmenli, Yakar ve Konca (2018) tarafından geliştirilen ölçeğin kullanılmasına karar verilmiş ve ilgili araştırmacılardan ölçeğin kullanılmasına yönelik izin alınmıştır. Sınıf öğretmeni adaylarının deprem bilgi düzeylerini belirlemek için araştırmacılar tarafından literatür taranmış ve deprem öncesi, deprem anı ve deprem sonrasına yönelik beş seçenekli 24 sorulardan oluşan bir başarı testi geliştirilmiştir.

Verilerin toplanması sürecinden önce ilgili üniversitelerden uygulama izinleri ve araştırmaya katılacak olan adaylardan aydınlatılış onam formu alınarak Kırşehir Ahi Evran Üniversitesi Sosyal ve Beşerî Bilimler Bilimsel Araştırma ve Yayın Etik Kurulu'na başvuru yapılmış ve etik kurul (Sayı:20/2 ve Tarih:25.07.2018) izni alınmıştır. Kullanılan fikir ve elde edilen veriler telif hakları düzenlemelerine uyularak kullanılmıştır.

\section{Bulgular}

Bu bölümde çalışmanın amaç ve alt amaçları doğrultusunda öğretmen adaylarının afet bilinci alg1 düzeyleri ve deprem bilgi düzeylerinin ne düzeyde olduğu ve afet algı düzeyleri ile deprem bilgi düzeyleri arasında ilişki olup olmadığına yönelik bulgulara yer verilmiştir.

\section{Sınıf Öğretmeni Adaylarının Afet Bilinci Algı Düzeylerine İlişsin Bulgular} verilmiştir.

Sınıf öğretmeni adaylarının afet bilinci algı düzeylerine ilişkin bulgular Tablo 3' de

Tablo 3

Sinıf Öğretmeni Adaylarının Afet Bilinci Algı Düzeyi

\begin{tabular}{|c|c|c|c|c|c|c|}
\hline $\begin{array}{l}\text { Afet Bilinci Algisı } \\
\text { Alt Bileşenleri }\end{array}$ & & Düşük & Orta & Yüksek & $\overline{\mathbf{x}}$ & $\mathbf{S}$ \\
\hline \multirow{3}{*}{$\begin{array}{l}\text { Afet Ĕgitimi } \\
\text { Bilinç Algısı }\end{array}$} & Aralık & $13-30$ & $31-48$ & $49-65$ & \multirow{3}{*}{54,88} & \multirow{3}{*}{6,91} \\
\hline & $\mathrm{f}$ & 8 & 41 & 503 & & \\
\hline & $\%$ & 1,4 & 7,5 & 91,1 & & \\
\hline \multirow{3}{*}{$\begin{array}{l}\text { Afet Öncesi } \\
\text { Bilinç Algis1 }\end{array}$} & Aralık & $8-18$ & $19-29$ & $30-40$ & \multirow{3}{*}{34,09} & \multirow{3}{*}{4,81} \\
\hline & $\mathrm{f}$ & 7 & 62 & 483 & & \\
\hline & $\%$ & 1,3 & 11,2 & 87,5 & & \\
\hline \multirow{3}{*}{$\begin{array}{l}\text { Yanlış Afet } \\
\text { Bilinç Algısı }\end{array}$} & Aralık & $8-18$ & $19-29$ & $30-40$ & \multirow{3}{*}{34,08} & \multirow{3}{*}{6,36} \\
\hline & $\mathrm{f}$ & 16 & 50 & 486 & & \\
\hline & $\%$ & 2,9 & 9,1 & 88 & & \\
\hline \multirow{3}{*}{$\begin{array}{l}\text { Afet Sonras1 } \\
\text { Bilinç Algıs1 }\end{array}$} & Aralık & $7-17$ & $18-26$ & $27-35$ & \multirow{3}{*}{23,58} & \multirow{3}{*}{5,36} \\
\hline & $\mathrm{f}$ & 95 & 385 & 72 & & \\
\hline & $\%$ & 17,2 & 69,8 & 13 & & \\
\hline \multirow{3}{*}{ Toplam } & Aralık & 36-84 & $85-132$ & $133-180$ & \multirow{3}{*}{146,64} & \multirow{3}{*}{17,43} \\
\hline & $\mathrm{f}$ & 7 & 69 & 476 & & \\
\hline & $\%$ & 1,3 & 12,5 & 86,2 & & \\
\hline
\end{tabular}


Tablo 3’te görüldüğü gibi ölçeğin alt boyutlarından afet eğitimi bilinç algısı boyutunda 13-30 puan arası düşük, 31-48 puan arası orta, 49-65 puan arası yüksek düzey olarak belirlenmiştir. Buna göre afet bilinç algısı 13-30 puan aralığına giren sınıf öğretmeni adaylarının oranı \%1,4; 31-48 puan aralığına giren öğretmen adaylarının oranı \%7,5; 49-65 puan aralığına giren öğretmen adaylarının oranı \%91,1'dir. Öğretmen adaylarının afet eğitimi bilinç algısı boyutundan aldıkları toplam puanın ortalaması $(\overline{\mathrm{X}}=54,88)$ bulunmuştur. Bu değere bakıldığında öğretmen adaylarının afet eğitimi bilinç algısı boyutundaki algılarının yüksek düzeyde olduğu söylenebilir.

Ölçeğin alt boyutlarından afet öncesi bilinç algısı boyutunda 8-18 puan arası düşük, 19-29 puan arası orta, 30-40 puan arası yüksek düzey olarak belirlenmiştir. Buna göre afet öncesi bilinç algısı boyutunda 8-18 puan aralığına giren ögretmen adaylarının oranı \%1,3; 19-29 puan aralığına giren öğretmen adaylarının oranı $\% 11,2 ; 30-40$ puan aralığına giren öğretmen adaylarının oranı \%87,5'tir. Öğretmen adaylarının afet öncesi bilinç algısı boyutundan aldıkları toplam puanın ortalaması $(\bar{X}=34,09)$ bulunmuştur. Bu değere bakıldığında öğretmen adaylarının afet öncesi bilinç algısı boyutundaki algılarının yüksek düzeyde olduğu söylenebilir.

Ölçeğin alt boyutlarından yanlış afet bilinç algısı boyutunda 8-18 puan arası düşük, 19-29 puan arası orta, 30-40 puan arası yüksek düzey olarak belirlenmiştir. Buna göre yanlış afet bilinç algısı boyutunda 8-18 puan aralı̆̆ına giren öğretmen adaylarının oranı \%2,9; 19-29 puan aralığına giren öğretmen adaylarının oranı $\% 9,1 ; 30-40$ puan aralığına giren öğretmen adaylarının oranı \%88'dir. Öğretmen adaylarının yanlış afet bilinç algısı boyutundan aldıkları toplam puanın ortalaması $(\overline{\mathrm{X}}=34,08)$ bulunmuştur. $\mathrm{Bu}$ değere bakıldığında öğretmen adaylarının yanlış afet bilinç algısı boyutundaki algılarının yüksek düzeyde olduğu söylenebilir.

Ölçeğin alt boyutlarından afet sonrası bilinç algısı boyutunda 7-17 puan arası düşük, 18-26 puan arası orta, 27-35 puan arası yüksek düzey olarak belirlenmiştir. Buna göre afet sonrası bilinç algısı boyutunda 7-17 puan aralığına giren öğretmen adaylarının oranı $\% 17,2 ; 18-26$ puan aralığına giren öğretmen adaylarının oranı $\% 69,8 ; 27-35$ puan aralığına giren öğretmen adaylarının oranı \%13, tür. Öğretmen adaylarının afet sonrası bilinç algısı boyutundan aldıkları toplam puanın ortalaması $(\overline{\mathrm{X}}=23,58)$ bulunmuştur. $\mathrm{Bu}$ değere bakıldığında öğretmen adaylarının afet sonrası bilinç algısı boyutundaki algılarının orta düzeyde olduğu söylenebilir.

Sınıf öğretmen adaylarının afet bilinci algı düzeylerinin belirlenebilmesi için afet eğitimi, afet öncesi, yanlış afet ve afet sonrası bilinç algısı boyutlarından oluşan ölçek kullanılmıştır. Öğretmen adaylarının afet bilinci algı düzeyleri bu alt boyutlardan aldıkları toplam puanların ortalamaları, standart sapmaları ve hangi düzeyde oldukları Tablo 2'de ayrı ayrı hesaplanmıştır. Buna göre öğretmen adaylarının ölçeğin genelinden alabilecekleri en yüksek puan 180'dir. Standartlaştırılmış puana göre, 36-84 puan aras1 düşük, 85-132 puan aras1 orta ve 133-180 puan aras1 yüksek afet bilinci algı düzeyi olarak belirlenmiştir. Buna göre afet bilinci algı ölçeğinde 36-84 puan aralığına giren öğretmen adaylarının oranı \%1,3; 85-132 puan aralığına giren öğretmen adaylarının oranı \%12,5; 133180 puan aralı̆̆ına giren öğretmen adaylarının oranı \%86,2'dir. Öğretmen adaylarının afet bilinci alg1 ölçeğinden aldıkları toplam puanın ortalaması $(\overline{\mathrm{X}}=146,64)$ belirlenmiştir. Bu değere bakıldığında öğretmen adaylarının afet bilinci algı düzeylerinin yüksek düzeyde olduğu söylenebilir.

\section{Sınıf Öğretmeni Adaylarının Deprem Bilgi Düzeylerine İlişkin Bulgular}

Sınıf öğretmeni adaylarının deprem bilgi düzeylerine ilişkin bulgular Tablo 4' de verilmiştir. 
Tablo 4

Sinıf Öğretmeni Adaylarının Deprem Bilgi Düzeyi

\begin{tabular}{|c|c|c|c|c|c|c|}
\hline $\begin{array}{l}\text { Deprem Bilgi } \\
\text { Düzeyleri Alt } \\
\text { Bileşenleri } \\
\end{array}$ & & Düşük & Orta & Yüksek & $\overline{\mathrm{x}}$ & $\mathbf{S}$ \\
\hline \multirow{3}{*}{ Deprem Bilgisi } & Aralık & $0-2$ & $3-4$ & $5-6$ & \multirow{3}{*}{3,02} & \multirow{3}{*}{1,25} \\
\hline & $\mathrm{f}$ & 179 & 309 & 64 & & \\
\hline & $\%$ & 32,4 & 56 & 11,6 & & \\
\hline \multirow{3}{*}{ Deprem Öncesi Bilgi } & Aralık & $0-2$ & $3-4$ & $5-6$ & \multirow{3}{*}{3,17} & \multirow{3}{*}{1,44} \\
\hline & $f$ & 175 & 271 & 106 & & \\
\hline & $\%$ & 31,7 & 49,1 & 19,2 & & \\
\hline \multirow{3}{*}{ Deprem Anı Bilgisi } & Aralık & $0-2$ & $3-4$ & $5-6$ & \multirow{3}{*}{3,38} & \multirow{3}{*}{1,34} \\
\hline & $\mathrm{f}$ & 132 & 305 & 115 & & \\
\hline & $\%$ & 23,9 & 55,3 & 20,8 & & \\
\hline \multirow{3}{*}{ Deprem Sonras1 Bilgi } & Aralık & $0-2$ & $3-4$ & $5-6$ & \multirow{3}{*}{2,70} & \multirow{3}{*}{1,32} \\
\hline & $\mathrm{f}$ & 249 & 250 & 53 & & \\
\hline & $\%$ & 45,1 & 45,3 & 9,6 & & \\
\hline \multirow{3}{*}{ Toplam } & Aralık & $0-8$ & $9-16$ & $17-24$ & \multirow{3}{*}{12,28} & \multirow{3}{*}{3,62} \\
\hline & $\mathrm{f}$ & 78 & 416 & 58 & & \\
\hline & $\%$ & 14,1 & 75,4 & 10,5 & & \\
\hline
\end{tabular}

Tablo 4' de görüldüğü gibi ölçeğin alt boyutlarından deprem bilgisi boyutunda 0-2 puan aras1 düşük, 3-4 puan arası orta, 5-6 puan arası yüksek düzey olarak belirlenmiştir. Buna göre deprem bilgisi 0-2 puan aralığına giren sınıf ögretmeni adaylarının oranı $\% 32,4$; 3-4 puan aralığına giren öğretmen adaylarının oranı \%56; 5-6 puan aralı̆̆ına giren öğretmen adaylarının oranı \%11,6'dır. Öğretmen adaylarının deprem bilgisi boyutundan aldıkları toplam puanın ortalaması $(\bar{X}=3,02)$ bulunmuştur. $\mathrm{Bu}$ değere bakıldığında öğretmen adaylarının deprem bilgisi boyutundaki algılarının orta düzeyde olduğu söylenebilir.

Ölçeğin alt boyutlarından deprem öncesi bilgi boyutunda 0-2 puan arası düşük, 3-4 puan arası orta, 5-6 puan arası yüksek düzey olarak belirlenmiştir. Buna göre deprem öncesi bilgi 0-2 puan aralığına giren öğretmen adaylarının oran $1 \% 31,7 ; 3-4$ puan aralığına giren öğretmen adaylarının oranı $\% 49,1 ; 5-6$ puan aralığına giren öğretmen adaylarının oranı \%19,2'dır. Öğretmen adaylarının deprem öncesi bilgi boyutundan aldıkları toplam puanın ortalaması $(\overline{\mathrm{X}}=3,17)$ bulunmuştur. $\mathrm{Bu}$ değere bakıldığında öğretmen adaylarının deprem öncesi bilgi boyutundaki algılarının orta düzeyde olduğu söylenebilir.

Ölçeğin alt boyutlarından deprem anı bilgisi boyutunda 0-2 puan arası düşük, 3-4 puan arası orta, 5-6 puan arası yüksek düzey olarak belirlenmiştir. Buna göre deprem anı bilgisi 0-2 puan aralığına giren öğretmen adaylarının oran $\% 23,9 ; 3-4$ puan aralığına giren öğretmen adaylarının oranı $\% 55,3 ; 5-6$ puan aralığına giren öğretmen adaylarının oranı \%20,8' dir. Öğretmen adaylarının deprem anı bilgisi boyutundan aldıkları toplam puanın ortalaması $(\overline{\mathrm{X}}=3,38)$ bulunmuştur. $\mathrm{Bu}$ değere bakıldığında öğretmen adaylarının deprem anı bilgisi boyutundaki algılarının orta düzeyde olduğu söylenebilir.

Ölçeğin alt boyutlarından deprem sonrası bilgi boyutunda 0-2 puan arası düşük, 3-4 puan arası orta, 5-6 puan arası yüksek düzey olarak belirlenmiştir. Buna göre deprem sonrası bilgi 0-2 puan aralığına giren öğretmen adaylarının oranı $\% 45,1 ; 3-4$ puan aralığına giren öğretmen adaylarının oranı $\% 45,3 ; 5-6$ puan aralığına giren öğretmen adaylarının oranı \%9,6' dır. Öğretmen adaylarının deprem sonrası bilgi boyutundan aldıkları toplam puanın ortalaması $(\overline{\mathrm{X}}=2,70)$ bulunmuştur. Bu değere bakıldığında öğretmen adaylarının deprem sonrası bilgi boyutundaki algılarının düşük düzeyde olduğu söylenebilir. 
Öğretmen adaylarının deprem bilgi düzeylerinin belirlenebilmesi için deprem bilgisi, deprem öncesi bilgi, deprem anı bilgisi ve deprem sonrası bilgi boyutlarından oluşan başarı testi kullanılmıştır. Öğretmen adaylarının deprem bilgi düzeyleri bu alt boyutlardan aldıkları toplam puanların ortalamaları, standart sapmaları ve hangi düzeyde oldukları Tablo 3'te hesaplanmıştır. Buna göre öğretmen adaylarının bu dört boyuttan yani ölçeğin genelinden alabilecekleri en yüksek puan 24'tür. Standartlaştırılmış puana göre, 0-8 puan arası düşük, 9-16 puan arası orta ve 17-24 puan arası yüksek deprem bilgi düzeyi olarak tespit edilmiştir. Buna göre deprem bilgisi başarı testinde 0-8 puan aralığına giren öğretmen adaylarının oranı \%14,1;9-16 puan aralığına giren öğretmen adaylarının oranı $\% 75,4 ; 17-24$ puan aralığına giren öğretmen adaylarının oranı $\% 10,5$ ' tir. Öğretmen adaylarının deprem bilgisi başarı testinden aldıkları toplam puanın ortalaması $(\overline{\mathrm{X}}=12,28)$ bulunmuştur. Bu değere bakıldığında öğretmen adaylarının deprem bilgi düzeylerinin orta düzeyde olduğu söylenebilir.

\section{Sınıf Öğretmeni Adaylarının Afet Bilinci Algısı ve Deprem Bilgi Düzeyi Arasındaki İlişkiye Yönelik Bulgular}

Grafik 1 incelendiğinde afet bilinci toplam puanlarının yüksek düzeyde gruplandığı; deprem bilgisi toplam puanlarının da aynı düzeyde gruplandığı görülmektedir. Bu durum değişkenler arasında güçlü pozitif ilişkiyi göstermekte olup; dağılım yönleri aynıdır. Dolayısı ile çıkarılabilecek sonuç; afet bilinci artarken deprem bilgisi başarı düzeyi de artmaktadır.

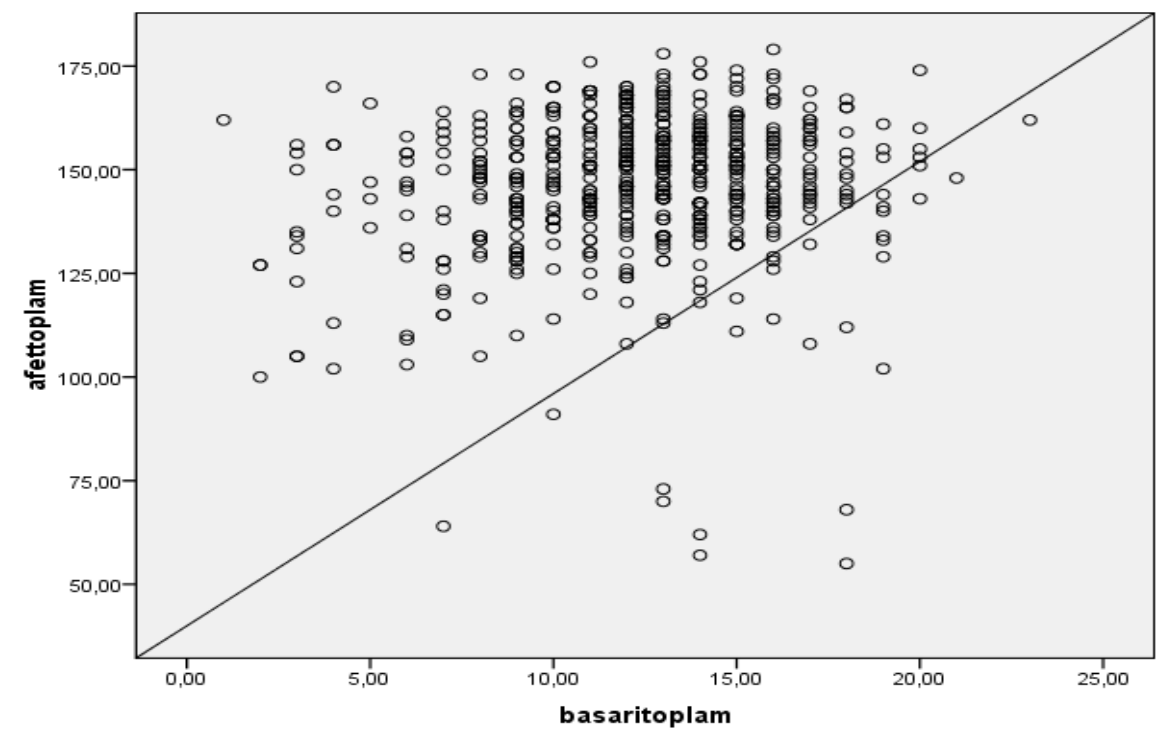

Grafik 1

Afet Bilinci Algl Ölçeğinden Alınan Toplam Puanlar ve Deprem Bilgisi Başarı Testinden Alınan Toplam Puanlar Arasındaki İlişkiyi Gösteren Saçılma Diyagramı

Sınıf öğretmeni adaylarının afet bilinci algı ölçeğinden alınan puanlarla deprem bilgisi başarı testi puanları arasındaki ilişkiyi belirlemek üzere yapılan analize ilişkin bulgular Tablo 5'te verilmiştir.

Tablo 5

Sinıf Öğretmeni Adaylarının Afet Bilinci Algı Ölçeğinden Alınan Puanlarla Deprem Bilgisi Başarı Testi Puanları Arasındaki İlişkiyi Belirlemek Üzere Yapılan Pearson Korelasyon Analizi Bulguları

\begin{tabular}{lccc}
\hline Değişkenler & $\mathbf{n}$ & $\mathbf{r}$ & $\mathbf{p}$ \\
\hline Afet Bilinci Algısı & 552 & 0,13 & 0,001 \\
Deprem Bilgisi Başarısı & 5 & & \\
\hline
\end{tabular}

Tablo 5'ten de anlaşılacağı üzere, sınıf öğretmeni adaylarının afet bilinci algısı ölçeğinden alınan puanlarla deprem bilgisi başarı testi puanları arasındaki ilişkiyi belirlemek üzere yapılan 
Pearson Korelasyon analizi sonucunda puanlar arasında, pozitif yönde ve istatistiksel açıdan anlamlı düzeyde bir ilişki olduğu saptanmıştır $(\mathrm{r}=0,13, \mathrm{p}<0.01)$. Bu sonuca göre sınıf öğretmeni adaylarının afet bilinci algı düzeyi artarken deprem bilgi düzeyinin arttığı, afet bilinci algı düzeyi azalırken de deprem bilgi düzeyinin azaldığı söylenebilir.

\section{Sonuç, Tartışma ve Öneriler}

$\mathrm{Bu}$ çalışmada öğretmen adaylarının afet bilinci algı düzeyleri, deprem bilgi düzeyleri ve afet bilinci algı düzeyleri ile deprem bilgi düzeyleri arasındaki ilişki değerlendirilmiştir.

Çalışmanın bulgularına göre sınıf öğretmeni adaylarının ölçeğin alt boyutları olan yüksek düzeyde afet eğitimi bilinç algısına, afet öncesi bilinç algısına, yanlış afet bilinç algısına ve genel afet bilinci algısına, orta düzeyde ise afet sonrası bilinç algısına sahip oldukları sonucuna ulaşılmıştır. Şahin, Lamba ve Öztop (2018) tarafından yapılan çalışmada bu çalışmaya paralel olarak üniversite öğrencilerinin afet bilinci düzeylerinin yüksek olduğunu belirlenmiștir. Yapılan bazı çalışmalarda öğretmen adaylarının afet bilinci algı düzeyleri orta düzey olarak tespit edilmiştir (Dikmenli ve Yakar 2019; Özkazanç ve Yüksel, 2015). İnal, Kocagöz ve Turan (2012) ise yüksekokul öğrencilerinde temel afet bilinç ve hazırlık düzeyinin düşük olduğunu belirlemiş ve bu sonuçlar çalışmanın bulgularıyla örtüşmemektedir. $\mathrm{Bu}$ çalışmada temel afet bilinci ve hazırlık düzeyinin düşük olması iki yıllık yüksekokul öğrencileri olmaları, coğrafya veya afet bilgisi konusunda ders almamış olmalarına bağlanabilir.

Çalışmanın bulgularına göre sınıf öğretmeni adaylarının orta düzeyde deprem bilgisi, deprem öncesi bilgi, deprem anı bilgi ve genel deprem bilgi düzeyine, düşük düzeyde deprem sonrası bilgi düzeyine sahip oldukları sonucuna ulaşılmıştır. Çalışmanın bulgularına bakıldığında sınıf öğretmeni adaylarının deprem bilgi düzeylerinin orta düzeyde olduğu belirlenmiştir. Literatürde deprem bilgi düzeyini belirleyen araştırmaya rastlanmamıştır. Öcal (2007a) tarafından öğretmen adaylarının deprem bilgilerini belirlemek üzere yapılan bir araştırmada düzey belirtmeden öğretmenlerin deprem hakkında yeterli bilgiye sahip olmadığını belirtilmiştir. Öğretmen adaylarının deprem bilgi düzeylerinde ve alt boyutlarda orta ve düşük düzeyde bilgiye sahip olmalarının nedeni aslında yapılan ve uygulanan politikalardan kaynaklandığı düşünülmektedir. Çünkü ülkemizde önleyici ve koruyucu afet ve deprem çalışmalarına (eğitim, yatırım, kentsel dönüşüm, ıslah gibi) yeterince önem verilmemektedir. Ancak afet olduktan sonra yaraların sarılması konusunda yani afet özelde de deprem olduktan sonra yapılması gerekenlere daha fazla özen gösteriliyor. Bu durum aslında ülkemizde afet ve deprem bilincinin de yeteri kadar oluşmadığının bir kanıtı olarak gösterilebilir.

Çalışmanın bulgularına göre, öğretmen adaylarının afet bilinci algı düzeyi artarken deprem bilgi düzeyi de artmaktadır. Puanlar arasında, pozitif yönde ve istatistiksel açıdan anlamlı düzeyde bir ilişki olduğu saptanmıştır. Afet bilinci algı düzeyi artarken deprem bilgi düzeyinin arttığı, afet bilinci alg1 düzeyi azalırken de deprem bilgi düzeyinin azaldığı söylenebilir. Literatür incelendiğinde doğal afetlerin çocuklar, yetişkinler, öğretmen adayları ve öğretmenler üzerindeki etkilerini, afet bilinci ve deprem bilgisi açısından ele alındığı çalışmalar mevcuttur. Son zamanlarda yapılan bu gibi çalışmalarda öğretmenlerin, öğrencilerin ve diğer tüm canlıların afete hazırlıklı olması, deprem bilgilerinin ve afet bilincinin oluşturulması, afetin olumlu ve olumsuz etkileri gibi konular üzerine odaklanıldığı saptanmıştır. Çalışmamızda ise sınıf öğretmeni adaylarının afet bilinci ve deprem bilgi düzeylerini daha iyi anlayabilmek adına doğal afetlerin etkileri geniş bir çerçevede ele alınmış yapılan çalışmalar eşliğinde farklılıklar ortaya konulmaya çalışılmıştır. Öğretmen adayları için doğal afet konularına olan ilgi durumları, dersi anlatan öğretim üyelerinim davranış tarzı, depreme yönelik bilgi ve ilgi düzeyleri ve çevresel etmenler afet bilincinin uyandırılması ve deprem eğitiminde başarı sağlayabilmeleri adına oldukça önem arz etmektedir. Literatüre bakıldığında afet bilinci algısı ve deprem bilgisi arasındaki ilişkiyi inceleyen herhangi bir yerli ya da yabancı çalışmaya rastlanmamıştır. $\mathrm{Bu}$ bağlamda bu araştırma literatüre önemli bir katkı sağlamakta ve öncül çalışma olarak ön plana çıkmaktadır. 


\section{Öneriler}

- Türkiye afetlerle iç içe olan bir ülke olarak öğretmen adaylarının afet bilincini ve deprem bilgi düzeyleri geliştirebilecek uygulamalı afet bilinci dersi konularak okutulması önerilebilir.

- Öğretmen adaylarının afetlere karşı daha bilinçli ve eğitimli olmaları konusunda ilgili kurum ve kuruluşlar (yerel yönetimler, üniversiteler, AFAD ve STK) ortak çalışmalar yapılabilir. Bu ortak çalışmalarla öğretmen adaylarına afetlerle ilgili eğitimler verilebilir, ortak tatbikatlarla afetlere ve depreme yönelik farkındalıkları arttırılabilir.

- Öğretmen adaylarının afet bilinci ve deprem bilgi düzeylerini artırmaya yönelik olarak üniversite çapında faal olarak çalışması sağlanan kulüpler oluşturulabilir ve öğretmen adaylarının bu kulüplerde aktif olarak görev almalarına özen gösterilebilir.

- Okullarda afet ve deprem konusunda öğrencileri bilgilendirecek olan öğretmen adaylarına afetlerle ilgili bilgi ve tecrübelerin kazandırılabilmesi için onların bu alanda iyi eğitim almaları için konu ile alakalı akademisyenlerin istihdamina yer verilebilir.

- Bu çalışma Amasya ve Kırşehir Ahi Evran üniversitelerindeki sınıf öğretmeni adayları ile sınırlıdır. Bundan sonra yapılacak çalışmalarda diğer üniversite ve branşlardaki öğretmen adaylarının da çalışmaya katılarak öğretmen adaylarının bilinç ve bilgi düzeylerine yer verilebilir.

- Bu çalışmada nicel araştırma yöntemleri benimsenmiştir. Bundan sonraki çalışmalarda afet bilinci alg1 düzeyini ve deprem bilgi düzeyini olumsuz etkileyebilecek sorunların belirlenmesi ve çözümüne yönelik nitel çalışmalara da yer verilmesi önerilebilir.

\section{Yazarların Katkı Oranı}

Bu makaleye birinci yazarın \%60, ikinci yazarın \%40 oranında katkısı vardır.

\section{Çıkar Çatışması}

Çıkar çatışması teşkil edebilecek bir durum yoktur.

Açıklamalar: $\mathrm{Bu}$ çalışma ikinci yazarın danışmanlığında birinci yazarın hazırladığı "Sınıf Öğretmeni Adaylarının Afet Bilinci Algısı ve Deprem Bilgi Düzeylerinin İncelenmesi” isimli Yüksek Lisans tezinden üretilmiştir.

\section{Kaynaklar}

Aydın, F. (2010). İlköğretim Sekizinci Sınıf Öğrencilerinin "Deprem” Kavramını Algılamaları: Fenomenografik bir analiz. Turkish Studies International Periodical For the Languages, Literature and History of Turkish or Turkic, 5(3), 801-817.

Başıüyük, A. (2004). Yetişkinlerde Deprem Bilgisi ve Etkili Faktörlerin İncelenmesi. Milli Eğitim Dergisi, 161(1), 215- 218.

Bingül, D., ve Çavaş, B. (2016). Fen Bilgisi Öğretmen Adaylarının Deprem Konusundaki Kavram Yanılgıları Üzerine Bir Araştırma. A. M. Ger (Ed.), Uluslararası Yükseköğretimde Yeni Eğilimler Kongresi: Değişime Ayak Uydurmak bildiriler kitabı içinde (89-96). İstanbul: İstanbul Aydın Üniversitesi.

Coveleski, J. (2014). A Study of Students' Perceptions of Natural Disaster Plans and Emergency Preparedness at a Higher Education Institution. Retrieved from http://purl.flvc.org/fsu/fd/FSU_migr_etd-9163. Erişim Tarihi:14.02.2020

Çakar, Ö. (2008). İlköğretim 5. Sınıf Sosyal Bilgiler Dersinin Deprem Bilinci Geliştirmedeki Rolüne Dair Öğretmen Görüşleri. Yüksek Lisans Tezi. Fırat Üniversitesi Sosyal Bilimler Enstitüsü, Elâzığ. 
Çoban, M. (2017). Üç Boyutlu Oyunla Yapılan Deprem Eğitiminin İlkokul Öğrencilerinin Akademik Başarıları ile Motivasyonlarına Etkisi ve Öğrencilerin Görüşleri. Yayımlanmamış Doktora Tezi. Atatürk Üniversitesi Eğitim Bilimleri Enstitüsü, Erzurum.

Değirmençay, Ş. A., ve Cin, M. (2016). Türkiye'deki Deprem Eğitimi Araştırmaları: Betimsel İçerik Analizi. Yüzüncü Yıl Üniversitesi Eğitim Fakültesi Dergisi, 13(1), 301-314.

Demirci A. ve Yıldırım, S. (2015). İstanbul'da Ortaöğretim Öğrencilerinin Deprem Bilincinin Değerlendirilmesi. Millî Eğitim Dergisi, 45(207), 89-118.

Demirkaya, H. (2007). İlköğretim 5, 6 ve 7. Sınıf Öğrencilerinin Depreme Yönelik Tutumlarının Çeşitli Değişkenlere Göre İncelenmesi. Türkiye Sosyal Araştırmalar Dergisi, 11(3), 37-51.

Dikmenli, Y., Danabaş, F., Çelik, B. B. and Tekin, Ö. (2018). Effects of Animation Film Use on Earthquake Knowledge Level of 4th Grade Students. Online Submission, 5(1), 86-95.

Dikmenli, Y. ve Yakar, H. (2019). Öğretmen Adaylarının Afet Bilinci Alg1 Düzeylerinin İncelenmesi. Yüzüncü Yll Üniversitesi Journal of Education Faculty, 16(1), 386-416.

Ergünay, O. (2008). Afet Yönetiminde Kurumsal Yapılanma ve Mevzuat Nedir? Nasıl Olmalıdır? İstanbul Depremi Beklerken Sorunlar ve Çözümler. Bildiriler Kitabı, CHP İstanbul Deprem Sempozyumu, 20 Eylül, İstanbul.

Fetihi, L. and Gülay, H. (2011). The Effect of Earthquake Awareness Development Program (EADP) on 6 Years old Children. International Online Journal of Educational Sciences, 3(2), 663-678.

Gay, L.R. and Diehl, P.L. (1992). Research Methods for Business and Management. New York: Max̄ well Macmillan International.

Gülay, H. (2010). An Earthquake Education Program With Parent Participation for Preschool Children. Educational Research and Review, 5(10), 624-630.

Hurnen, F. and Mcclure, J. (1997). "The Effect of Increased Earthquake Knowledge on Perceived Preventability of Earthquake Damage". The Australasian Journal of Disaster and Trauma Studies (Electronic Journal), 3.

İnal, E., Kocagöz, S. ve Turan, M. (2012). Temel Afet Bilinç ve Hazırlık Düzeyinin Saptanmasına Yönelik Bir Araştırma. Türkiye Acil Tip Dergisi, 12(1), 15-19.

İzbırak, R. (1992). Coğrafya Terimleri Sözlüğü. Ankara: Millî Eğitim Bakanlığı Yayınları.

Karakuş, U. (2013). Depremi Yaşamış ve Yaşamamış Öğrencilerin Deprem Algılarının, Metafor Analizi ile İncelenmesi. Doğu Coğrafya Dergisi, 18(29), 97-116.

Karasar, N. (1999). Bilimsel Araştırma Yöntemleri. Ankara: Nobel Yayın Dağıtım.

Kıvrak, Ö. (2019). Karabük İlinde Deprem Farkındalı̆̆ Mevcut Durumunun ve Deprem Eğitiminin Ögrenciler Üzerindeki Etkisinin Araştırılması. Yüksek Lisans Tezi. Karabük Üniversitesi Fen Bilimleri Enstitüsü, Karabük.

Öcal, A. (2005). İlköğretim Sosyal Bilgiler Dersinde Deprem Eğitiminin Değerlendirilmesi. Gazi Ĕ̈itim Fakültesi Dergisi, 25(1),169-184. 
Öcal, A. (2007a). İlköğretim Aday Öğretmenlerinin Deprem Bilgi Düzeyleri Üzerine bir Araştırma. Mehmet Akif Ersoy Üniversitesi Eğitim Fakültesi Dergisi, 8(1), 104-110.

Öcal, A. (2007b). İlköğretim Okullarında Deprem Hazırlıkları: Kırıkkale İli Örneği. Kastamonu Eğitim Dergisi, 15(1), 1-12.

Özkazanç, S. and Yüksel, Ü. D. (2015). Evaluation of Disaster Awareness and Sensitivity Level of Higher Education Students. Procedia-Social and Behavioral Sciences, 197, 745-753.

Öztürk, M. K. (2013). Sınıf Öğretmeni Adaylarının Deprem Deneyimleri Üzerine Bir Araştırma. Hacettepe Üniversitesi Eğitim Fakültesi Dergisi, 28(1), 308-319.

Özgen, N., Ünaldı, Ü. E. ve Bindak, R. (2011). Öğretmen Adaylarının Doğal Afetler Konusuna Yönelik Etkili Öğrenme Biçimlerinin Belirlenmesi. Ahi Evran Üniversitesi Kırşehir Eğitim Fakültesi Dergisi, 12(4), 303-323.

Panić, M., Kovačević-Majkić, J., Miljanović, D. and Miletić, R. (2013). Importance of Natural Disaster Education-Case Study of the Earthquake Near the City of Kraljevo: First Results. Journal of the Geographical Institute Jovan Cvijic, SASA, 63(1), 75-88.

Shaw, R., Kobayashi, K. S. H. and Kobayashi, M. (2004). Linking Experience, Education, Perception and Earthquake Preparedness. Disaster Prevention and Management, 13(1), 39-49.

Sönmez, V. ve Alacapınar, F. (2011). Bilimsel Araştırma Yöntemleri. Ankara: Anı Yayıncılık.

Sönmez, V. ve Alacapınar, F.G. (2013). Örneklendirilmiş Bilimsel Araştırma Yöntemleri. Ankara: An1.

Sür, Ö. (1993). Türkiye'nin Deprem Bölgeleri. Ankara Üniversitesi Türkiye Coğrafyası Araştırma ve Uygulama Merkezi Dergisi, (2), 53-65.

Şahin, C. (1991). Türkiye Afetler Coğrafyası. Ankara: Gazi Üniversitesi Yayın No:172, GEF Yayın No: 21.

Şahin, Y., Lamba, M. ve Öztop, S. (2018). Üniversite Öğrencilerinin Afet Bilinci ve Afete Hazırlık Düzeylerinin Belirlenmesi. Medeniyet Araştırmaları Dergisi, 3(6), 149-159.

Tanaka, K. (2005). The İmpact of Disaster Education on Public Preparation and Mitigation for Earthquakes: A Cross-Country Comparison Between Fukui, Japan and the San Francisco Bay Area, California, USA. Applied Geography, 25(3), 201-225.

Taş, G. (2003). Türkiye'de Ortaöğretim Kurumlarında Doğal Afetler (deprem, kütle hareketleri, volkan, don olayı) Konularının Öğretiminin Değerlendirilmesi. Yayınlanmamış Yüksek Lisans Tezi. Gazi Üniversitesi Eğitim Bilimleri Enstitüsü, Ankara.

Yazıcı, Ö. ve Ulu Kalın, Ö. (2018). Doğal Afet için Kavramsal Metaforların Karşılaştırmalı Analizi. eKafkas Eğitim Araştırmaları Dergisi, 5(1), 25-40. 


\section{Extended Abstract}

\section{Introduction}

Disasters are events induced by nature, technology, and human factors that cause physical, economic, and social losses, affect societies by interrupting or halting normal life and human activities. Effective disaster awareness and education are necessary to protect against the harmful effects of a disaster or to minimise all possible damages.

One of the most important natural disasters in our country is an earthquake. It is not possible to predict or prevent the earthquake. People can take the necessary precautions to elude an earthquake with minimum damage. The most important precaution is effective and continuous earthquake education.

When the literature is reviewed, various studies on disaster awareness can be found. However, there are no studies that determine the relationship between disaster awareness perception and earthquake knowledge level. The purpose of this study is to determine the pre-service classroom teachers' disaster awareness perception and earthquake knowledge level and whether there is a relationship between disaster awareness and earthquake knowledge.

\section{Method}

This study is conducted with relational survey model to analyse pre-service classroom teachers' disaster awareness perception and earthquake knowledge level and to determine the relationship between these two concepts.

The sample of this study is 552 pre-service classroom teachers in Ahi Evran University and Amasya University in 2018-2019 term. The convenience sampling method is employed in this study.

In this study, "Disaster Awareness Perception Scale" is used for determining the pre-service classroom teachers' disaster awareness perception level and "Earthquake Knowledge Success Test" is used for determining the pre-service classroom teachers' earthquake knowledge level. The obtained data are investigated with quantitative analysis methods. For the descriptive presentation of the obtained data, frequency, percentage, average and standard deviation are used.

\section{Findings}

The total average score for pre-service teachers' disaster education awareness perception dimension is found as $(\overline{\mathrm{X}}=54.88)$. When this value is considered, it can be said that pre-service teachers' disaster education awareness perception dimension perception is at a high level. The total average score for pre-service teachers' pre-disaster awareness perception dimension is found as $(\overline{\mathrm{X}}$ $=34.09$ ). When this value is considered, it can be said that pre-service teachers' pre-disaster awareness perception dimension perception is at a high level. The total average score for pre-service teachers' incorrect disaster awareness perception dimension is found as $(\overline{\mathrm{X}}=34.08)$. When this value is considered, it can be said that pre-service teachers' incorrect disaster awareness perception dimension perception is at a high level. The total average score for pre-service teachers' post-disaster awareness perception dimension is found as $(\overline{\mathrm{X}}=23.58)$. When this value is considered, it can be said that preservice teachers' post-disaster awareness perception dimension perception is at a medium level. The total average score for pre-service teachers' disaster awareness perception scale is found as ( $\bar{X}$ $=146.64)$. When this value is considered, it can be said that pre-service teachers' disaster awareness perception is at a high level. The total average score for pre-service teachers' earthquake knowledge dimension is found as $(\overline{\mathrm{X}}=3.02)$. When this value is considered, it can be said that pre-service teachers' earthquake knowledge dimension perception is at a medium level. The total average score for pre-service teachers' pre-earthquake knowledge dimension is found as $(\overline{\mathrm{X}}=3.17)$. When this value 
is considered, it can be said that pre-service teachers' pre-earthquake knowledge dimension perception is at a medium level. The total average score for pre-service teachers' earthquake moment knowledge dimension is found as $(\overline{\mathrm{X}}=3.38)$. When this value is considered, it can be said that pre-service teachers' earthquake moment knowledge dimension perception is at a medium level. The total average score for pre-service teachers' post-earthquake moment knowledge dimension is found as $(\overline{\mathrm{X}}=2.70)$. When this value is considered, it can be said that pre-service teachers' post-earthquake knowledge dimension perception is at a low level. The total average score for pre-service teachers' earthquake knowledge success test is found as $(\overline{\mathrm{X}}=12.28)$. When this value is considered, it can be said that preservice teachers' earthquake knowledge success test is at a medium level.

As a result of the Pearson Correlation analysis conducted to determine the relationship between pre-service classroom teachers' disaster awareness perception scale score and earthquake knowledge success test score, it is seen that there is a positive and statistically significant relationship ( $\mathrm{r}=0.13, \mathrm{p}<0.01)$. Accordingly, it can be said that as pre-service classroom teachers' disaster awareness perception level increased, their earthquake knowledge level increased; as disaster awareness perception level decreased, their earthquake knowledge level decreased.

\section{Conclusion, Discussion and Recommendations}

According to the findings of this study, it is found that pre-service classroom teachers' have high-level disaster education awareness perception, pre-disaster awareness perception, incorrect disaster awareness perception and general disaster awareness perception and medium-level postdisaster awareness perception for scale and scale sub-dimensions. Although there are few studies to increase disaster awareness perception and determine the perception level in the literature, there are studies that both support and do not support this finding.

According to the study findings, it is found that pre-service classroom teachers have mediumlevel earthquake knowledge, pre-earthquake, earthquake and general earthquake knowledge level and low-level post-earthquake knowledge. When the findings are considered, it is found that pre-service classroom teachers' earthquake knowledge success test is at a medium level.

According to the study findings, the pre-service teachers' earthquake knowledge level increases as their disaster awareness perception level increases. A positive and statistically significant relationship is found between the scores. It can be said that as pre-service classroom teachers' disaster awareness perception level increased, their earthquake knowledge level increased; as disaster awareness perception level decreased, their earthquake knowledge level decreased.

- Since Turkey is a country with high disaster prevalence, applications to improve pre-service teachers' disaster awareness and earthquake knowledge level can be included in the disaster awareness class.

- To increase pre-service teachers' disaster awareness and earthquake knowledge level, active clubs can be formed in the universities and pre-service teachers can be encouraged to actively participate in these clubs.

- This study is limited to pre-service classroom teachers in Amasya and Kırşehir Ahi Evran University. The future studies might include other universities and other pre-service teacher branches to assess awareness and knowledge level.

- This study adopted quantitative research methods. Future studies might include qualitative studies to determine the problems that might have a negative impact on disaster awareness perception level and earthquake knowledge level and possible solutions. 